\title{
EL JAPONISMO EN LLUÍS DOMÈNECH I MONTANER Y SU COLECCIÓN DE LIBROS ILUSTRADOS JAPONESES
}

\author{
RICARD BRU TURULL ${ }^{1}$ \\ Universitat Autònoma de Barcelona
}

\begin{abstract}
Este artículo presenta la relación de Lluís Domènech i Montaner con el arte japonés a través del fenómeno del japonismo difundido en Cataluña a finales del siglo XIX poniendo especial énfasis en los vínculos entre su obra, su biblioteca y su colección particular de libros ilustrados japoneses.
\end{abstract}

Palabras clave: japonismo; modernismo; coleccionismo; arte japonés; ehon.

\section{LLUÍS DOMÈNECH I MONTANER'S JAPONISME AND HIS COLLECTION OF JAPANESE ILLUSTRATED BOOKS}

This article presents the impact of Japanese art on Lluís Domènech i Montaner's work through the phenomenon of Japonisme disseminated in Catalonia toward the end of the $19^{\text {th }}$ century. The research places special emphasis on the connection between his architecture, his library and his private collection of Japanese illustrated books.

Key words: japonisme; modernism; collecting; Japanese art; ehon.

Cómo citar este artículo / Citation: Bru Turull, Ricard (2018): "El japonismo en Lluís Domènech i Montaner y su colección de libros ilustrados japoneses”. En: Archivo Español de Arte, vol. 91, núm. 363, Madrid, pp. 285-300. https://doi.org/10.3989/aearte 2018.18.

El japonismo, la atracción, la influencia y la inspiración que generaron las artes de Japón, es uno de los fenómenos de incidencia artística del sigo XIX fundamentales para comprender el nacimiento del modernismo y la evolución del arte durante las últimas décadas del ochocientos, tanto en el conjunto de Europa como, de un modo más local, en la España de finales del siglo XIX y en Cataluña en particular. Tal y como se ha señalado en repetidas ocasiones, los artistas catalanes de aquel tiempo se sintieron seducidos por un arte, el japonés, que generó en ellos una atracción de consecuencias múltiples y muy diversas. El ferviente coleccionismo entre pintores, escultores, decoradores e industriales es una de las muchas expresiones de este fenómeno que impregnó la cotidianidad de clases altas, medias y populares. Y es que, ciertamente, fueron muchos los artistas que adquirieron libros, estampas y objetos decorativos japoneses ${ }^{2}$. No es de extrañar, por lo tanto, que la estética japonesa también fuera bien recibida por arquitectos jóvenes como Antoni Gaudí, Josep Vilaseca o Lluís Domènech i Montaner.

El nacimiento del japonismo como fenómeno global vivido por toda Europa y América hay que situarlo principalmente en Francia, Inglaterra y Estados Unidos entre las décadas de 1850 y

\footnotetext{
1 ricard.bru@uab.cat / ORCID iD: http://orcid.org/0000-0001-6206-0058.

2 Para una primera introducción al japonismo y coleccionismo de arte japonés en Cataluña, véase: Bru, 2013; Bru, 2014: 51-86.
}

Copyright: (C) 2018 CSIC. Este es un artículo de acceso abierto distribuido bajo los términos de una licencia de uso y distribución Creative Commons Reconocimiento 4.0 Internacional (CC BY 4.0) 
1870, especialmente a partir de la celebración de la Exposición Universal de París de 1867. Sin embargo, rápidamente se difundió cruzando fronteras, de Suecia a Italia, desde España hasta Polonia y Hungría. En Cataluña, el japonismo empezó a tomar forma a caballo entre los años 70 y 80, para a continuación implantarse con una incidencia profunda que afectó de una manera intensa a las artes decorativas y a la decoración de interiores de muchos nuevos edificios y viviendas particulares. Desde este punto de vista, industriales, decoradores y arquitectos jugaron también un rol importante en la implantación y difusión del japonismo en Cataluña. En este contexto, este estudio da a conocer la relación de Lluís Domènech i Montaner con el fenómeno del japonismo así como su colección de libros ilustrados japoneses.

\section{Japonismo y arquitectura en torno al modernismo}

La incidencia del japonismo en la arquitectura catalana de 1900 hay que entenderla en dos sentidos. Por un lado, una incidencia epidérmica basada en la introducción de motivos decorativos aplicados al espacio arquitectónico proyectados tanto por arquitectos como por decoradores e industriales, $y$, por el otro, una incidencia mucho más puntual aunque más sustancial y profunda basada en la aplicación de formas y recursos constructivos extraídos de los modelos japoneses. Ambas aproximaciones comenzaron a ser posibles a partir de la década de 1880, cuando el arte japonés se extendió por Barcelona y cuando muchos de sus habitantes pudieron conocer algunas de las particularidades de la arquitectura nipona a través de diversas iniciativas.

Los principios de la arquitectura japonesa fueron descubiertos a partir de la década de 1870 gracias tanto al acceso a publicaciones europeas de la época, revistas y monografías, como especialmente fruto del impacto que produjeron los recintos, casas y pabellones levantados por el gobierno japonés y por la empresa Kiriu Kōshō Kaisha en ocasión de las exposiciones universales celebradas en París (1867, 1878, 1889 y 1900), Viena (1873), Filadelfia (1876), Barcelona (1888) y Chicago (1893). En paralelo, la presencia de edificios japoneses como los de la Japanese Native Village construida en 1885 en el barrio de Knightsbrige de Londres, así como la casa Midori no sato (1886) construida por Huges Kraftt en Les Loges-en-Josas, en las afueras de París, o bien el recinto de La Tour Japonaise de Bruselas, inaugurado en 1905, así como centenares de interiores particulares como el salón japonés (1886) de la Maison de Pierre Loti, en Rochefort, o la casa de Mortimer Menpes, en Londres, son muestras evidentes de cómo la arquitectura japonesa también tuvo un papel relevante en el seno del fenómeno del japonismo en Europa.

En Barcelona, una de las primeras aproximaciones a la arquitectura japonesa la protagonizó el Pabellón Imperial Japonés impulsado por la sociedad anónima Imperial Japonesa creada en junio de 1881 por los escenógrafos Fèlix Urgellés y Miquel Moragas y el viajero y coleccionista Carles Maristany ${ }^{3}$. El objetivo de dicha sociedad fue el de construir una exposición temporal para mostrar la colección de arte japonés adquirida por Maristany durante su larga estancia en Japón en 1880. A tal fin, Urgellés y Moragas proyectaron un edificio destinado a contener varias vistas panorámicas y escenografías en las cuales se mostraron todo tipo de objetos artísticos y etnográficos. Según puede observarse en las distintas ilustraciones y en varias descripciones, el edificio fue diseñado con una fachada que reproducía la arquitectura tradicional japonesa, con la característica puerta de techo ondulado karamon y, teniendo como referente "las puertas del famoso templo de Chiva [Shiba]", es decir, el desaparecido mausoleo de los Tokugawa del templo Zōzōji, en Tokio ${ }^{4}$.

Fueron muchos los arquitectos y artistas de la época que tuvieron ocasión de ver edificios japoneses como los que se levantaron en las exposiciones internacionales de Viena y de París.

\footnotetext{
${ }^{3}$ No debemos confundirlo con el llamado Grandioso Pabellón Japonés alzado dos años antes en el mismo solar (Bru, 2011: 244-231, 373-385).

${ }^{4}$ La Correspondencia de España, Madrid, 11-V-1882: 3. Bru, 2011: 380.
} 
Sin embargo, en el caso catalán, aparte de este vínculo con el extranjero es importante resaltar el impacto que tuvo la construcción de una casa tradicional japonesa en el recinto de la Exposición Universal de Barcelona de 1888, traída desde Tokio por la Kiriu Kōshō Kaisha ${ }^{5}$. La presencia de la casa japonesa, construida en el parque de la Ciutadella bajo la dirección del carpintero Ishimura Hikojirō en marzo de 1888, y abierta a los visitantes entre los meses de abril y diciembre del mismo año, no deja margen a la duda respecto al conocimiento directo de los modelos constructivos tradicionales japoneses que pudieron descubrir y estudiar de primera mano arquitectos como Antoni Gaudí, Josep Vilaseca o Lluís Domènech i Montaner. Gaudí, Vilaseca y Domènech fueron algunos de los principales arquitectos de ese certamen y, por lo tanto, resulta lógico suponer el interés que debió despertar en ellos un edificio de madera completamente singular, distinto a todos los otros y alzado siguiendo unas técnicas constructivas diferentes a las occidentales. Así lo narraba el crítico de arte Antonio García Llansó, colaborador de Domènech en su Historia General del Arte, desde las páginas de La Ilustración:

Varias veces durante el período empleado en su construcción, hemos contemplado, hasta con asombro, la inteligencia del carpintero japonés, así como las especiales herramientas que emplea y la manera de usarlas. Gruesos escoplos de bien templado acero, azuelas de pequeña y cortante hoja unida a largo mango, cepillos, sierras, martillos y otros ingenios originales y desconocidos, los hemos visto manejados con seguridad y precisión por hombres de tostada tez, de facciones duras, cubiertos con ajustados trajes de lienzo azul oscuro, silenciosos y activos, poseídos de su cometido y seguros de su habilidad. Hemos admirado su maestría al cortar la madera con la azuela, de modo que cada corte se confundía con el anterior, de tal manera que al terminar la tarea no se percibía la menor muesca cual si se hubiera cortado de un solo golpe, o bien manejar la sierra y el cepillo en dirección opuesta a la de nuestros carpinteros, esto es, de fuera adentro y practicar admirables ajustes o ensamblajes sin el auxilio de la escuadra. Preciso es reconocer la habilidad del carpintero japonés. Atestíguanlo no sólo los ligeros pormenores que apuntamos, sí que también el pulimento de las maderas por medio del cepillo sin el auxilio de la escofina y especialmente el admirable sistema de ensamblar las piezas que hace posible el desmontaje de la casa sin que sufran las maderas el menor desperfecto, ya que no se utilizan clavos para su sujeción. Si no reuniera condiciones de habitabilidad, podría considerarse como un gran mueble, tal es su bello aspecto, lo delicado de sus labores, algunos de las cuales asemejan a los trabajos de filigrana, y a la rica sencillez de los materiales empleados en su construcción, entre los que figuran la Crypsomeria japónica (enebro japones), el schitan, etcétera ${ }^{6}$.

García Llansó y arquitectos del momento, como Bonaventura Bassegoda, observaron y aprendieron como eran algunos de los aspectos característicos de la arquitectura tradicional mediante una casa que disponía no solo del tradicional genkan, acceso en el cual los visitantes se descalzaban para entrar a una estancia interior con tatami, sino también toda una nueva concepción del espacio, sin muros de carga, con espacios abiertos y modulares a través de puertas correderas. De este modo, más allá de propuestas singulares como el Pabellón Imperial Japonés, lo cierto es que la Exposición Universal de 1888 significó un momento destacado en cuanto a la aproximación de los artistas y arquitectos locales a las artes y a la arquitectura japonesa ${ }^{7}$.

Los modelos arquitectónicos nipones comenzaron a ser explorados de forma muy esporádica y puntual durante los años ochenta de la mano de jóvenes arquitectos como Cristóbal Cascante y Antoni Gaudí, el primero de ellos con un pabellón de madera y de cristal de Comillas conocido como la caseta del rey, y el segundo en algunos elementos estructurales y decorativos varios de edificios de su etapa de juventud como los pabellones Güell, la casa Vicens y el Palau Güell ${ }^{8}$. Sin embargo, como apuntábamos anteriormente, el contacto con el japonismo tuvo, en términos

\footnotetext{
5 Archivos Diplomáticos del Ministerio de Asuntos Exteriores de Japón, Supeinkoku Baruseronu fukaisetsu Bankoku Hakurankai Teikoku seifu sandō ikken, s/n, 24 de junio de 1887. Bru, 2011: 521-522.

6 García, 1888: 418.

7 Bru, 2011: 267-278, 373-385.

8 Arnús, 2004: 16, 35, 40; Torii, 2002: 118-137. Bru, 2011: 947-961.
} 
generales, un efecto más superficial, epidérmico y decorativo, aunque al mismo tiempo más impactante, en un número destacado de edificios proyectados, construidos o decorados entre las décadas de 1880 y 1910. Ello fue fruto no tanto del conocimiento de la arquitectura japonesa como principalmente de la atracción por la estética tradicional nipona.

La adquisición de estampas y libros ilustrados japoneses del siglo XIX fue frecuente entre los artistas y rápidamente se convirtió en uno de los mejores medios para conseguir modelos fidedignos a partir de los cuales poder plantear la decoración tanto de fachadas como especialmente de los salones japoneses que se fueron poniendo de moda entre las clases acomodadas ${ }^{9}$. Dos ejemplos paradigmáticos son la reforma de la casa de paraguas, sombrillas y abanicos de Bruno Cuadros, llevada a cabo entre 1885 y 1895, así como la decoración del salón japonés de la casa Coll i Pujol de Badalona, atribuida a Félix Urgellès, hacia 1897. En el primer caso, varios dibujos de Vilaseca demuestran cómo el arquitecto partió del estudio de libros de repertorios y del calco de estampas japonesas, como el tríptico Arashiyama sakuragari no zu (1854) de Utagawa Kunisada; obras que fueron utilizadas como punto de partida para las escenas esgrafiadas que decoraban la fachada del establecimiento ${ }^{10}$. Asimismo, la observación atenta de la pintura que decoraba los muros del antiguo salón japonés de la casa Coll i Pujol muestra como estos no son más que la adaptación libre y original de varios fragmentos de estampas yakusha-e del siglo XIX, como otro tríptico de Utagawa Kunisada de 1827. En este sentido, tenemos constancia de varios ejemplos similares que vienen a confirmar cómo este tipo de estampas japonesas fueron utilizadas recurrentemente de forma mimética como recurso decorativo para numerosos proyectos paradigmáticos de la época del modernismo en Cataluña. Como veremos, Domènech i Montaner no quedó al margen.

Finalmente, aparte del estudio y la aplicación de principios propios de la arquitectura tradicional japonesa, así como de la introducción de elementos decorativos de carácter más epidérmico extraídos del arte japonés, no hay que olvidar la presencia de otros proyectos en los que la modernidad artística del fin de siglo comenzó a integrar de una manera armónica y natural elementos estructurales y decorativos tanto de raíz europea como japonesa; serían dos buenos ejemplos la Pecera del Liceo, decorada por Josep Pascó, así como la sala de música de la sede de la Asociación Wagneriana, de Adrià Gual.

\section{Lluís Domènech i Montaner y las artes de Japón}

Lluís Domènech i Montaner puede ser considerado, junto con su amigo y compañero de profesión Josep Vilaseca, uno de los arquitectos catalanes que más se sintieron atraídos por las artes de Japón. Por tanto, es lógico comprobar como tal fascinación rezumó y se hizo presente en aspectos diversos de su obra. En este sentido, hay que pensar que, tanto en el caso de Domènech como en el de Vilaseca, el descubrimiento del arte japonés se produjo como resultado natural de unas inquietudes profesionales que les llevaron a mirar hacia Europa y a estudiar los nuevos planteamientos arquitectónicos y estéticos descubiertos durante sus años de formación y de juventud.

En el caso de Domènech i Montaner, el interés inicial por la estética japonesa la podemos descubrir durante la década de 1880 en proyectos vinculados al renacimiento de las artes decorativas e industriales de Barcelona. Este fue el caso de la encuadernación del volumen manuscrito Aplech de versos de Blancafort (pseudónimo de Pere Coromines), realizada hacia 1888 en los

\footnotetext{
9 Bru, 2007: 53-61.

${ }_{10}$ A pesar de que en el interior se mantiene intacta la gran decoración original del techo, en cambio, las escenas de la fachada esgrafiadas hacia 1885 ya no se conservan; fueron sustituidas por las actuales, encargadas por Bruno Cuadros al pintor decorador A. Vilaró en marzo de 1915. Por otro lado, la reproducción de la pintura Honoo (La llamarada, 1918) de Uemura Shōen que figura en la esquina del edificio no fue añadida hasta la década de 1980 a iniciativa del arquitecto Jordi Romeu durante las obras de rehabilitación de la fachada (1983-1989). Bru, 2013: 66, 109 (Bru, 2017: 216-217).
} 
talleres del padre del arquitecto, Pere Domènech i Saló (fig. 1) ${ }^{11}$. La encuadernación del Aplech parte del uso de una base a modo de greca geométrica repetitiva en la cual se sobreponen motivos circulares de inspiración japonesa, tales como una flor de crisantemo y varias libélulas. Estos últimos motivos posiblemente están inspirados en los diseños del libro Iroha-biki monchō (1881), una obra de la propia biblioteca del arquitecto (fig. 2) en la cual se recogían alfabéticamente cuantiosos ejemplos de símbolos heráldicos japoneses (mon) así como otros diseños circulares y símbolos recurrentes del arte japonés, como los Genjimon (Genjikō). De todos modos, más allá del volumen Iroha-biki monchō, no descartamos la posibilidad de que el arquitecto pudiera utilizar paralelamente otras fuentes, en tanto que conviene no olvidar otras publicaciones destacadas de la época, como es el caso del volumen de Thomas W. Cutler titulado A grammar of Japanese ornament and design (1880), publicación a la cual pudo acceder a través de su compañero Josep Vilaseca ${ }^{12}$. En cualquier caso, diseños como los de la

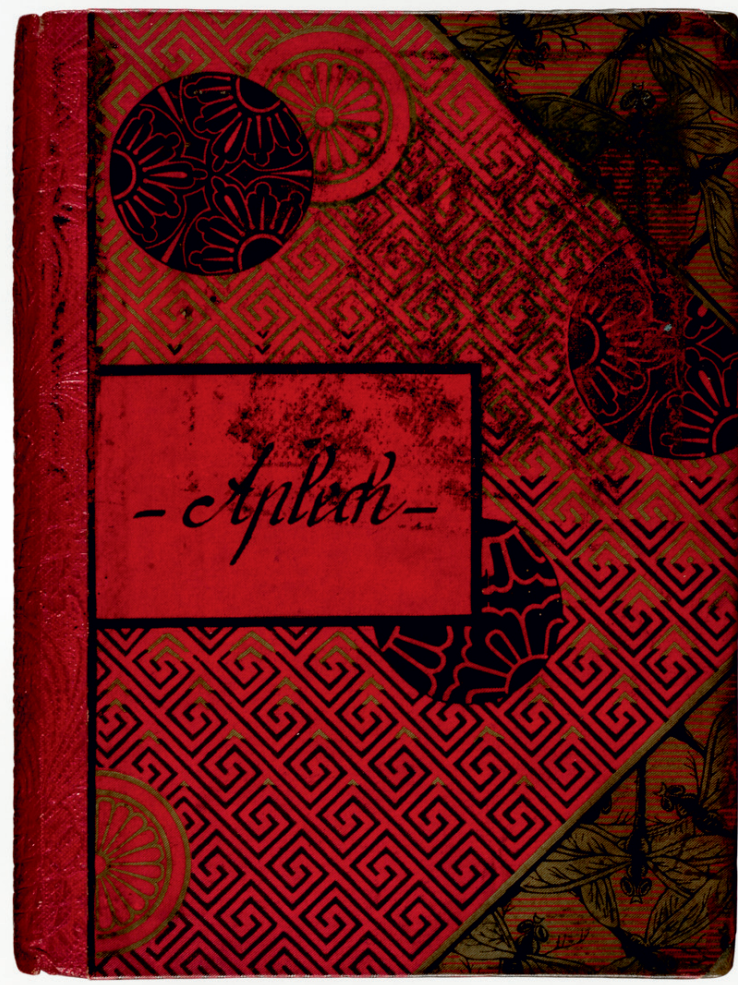

Fig. 1. Aplech, c. 1888. Encuadernación de E. Domenech y Cía. Biblioteca de Catalunya. encuadernación del volumen Aplech muestran una forma de componer muy parecida a la que a la sazón utilizaban artistas y arquitectos ingleses como Dante Gabriel Rossetti, Edward William Godwin y William Eden Nesfield en el contexto del Aesthetic movement ${ }^{13}$. Igualmente, varios de los primeros proyectos destacados del arquitecto incorporaron el japonismo mediante la aplicación de motivos a través de las artes decorativas y especialmente las vidrieras, como los cristales decorados con motivos esteticistas y de estilo japonés que realizó Antoni Rigalt para el Palau Ramon Montaner y el Café-Restaurante de la Exposición Universal de 1888. En ambos casos, se trataba de edificios en los cuales se combinaban formas naturalistas y modernas características del esteticismo catalán junto con escenas de temática japonesa en las cuales aparecían desde mujeres con quimono hasta la representación del monte Fuji ${ }^{14}$. En este sentido, cabe recordar también la presencia de varias figuras japonesas dibujadas por Ferran Xumetra para decorar el interior del Café-Restau-

11 En este caso, el emblema del negocio familiar, con la leyenda D. y Cia - Labore - Fortuna - Asservit, no permite precisar la autoria y determinar con seguridad si se trata de un diseño de Lluís o de su hermano Eduard Domènech i Montaner, heredero del negocio del padre (Bru, 2011: 804-805).

12 Varios de los diseños dibujados por Josep Vilaseca para decorar la Casa Bruno Cuadros fueron copiados de la obra de Cutler. Dicha obra no ha podido ser documentada en la biblioteca de Lluís Domènech i Montaner aunque algunas de las ilustraciones de los volúmenes de la Historia General del Arte son las mismas que publicaron Cutler y otros autores del momento. Asimismo, los motivos utilizados por Domenech y Cía aparecen en muchas de las publicaciones europeas de la época dedicadas al arte japonés (Bletter, 197: 97).

13 Véase, a modo de ejemplo, la encuadernación de Rossetti para la obra de Algernon Charles Swinburne Songs Before Sunrise (1871) o bien los diseños para el Cloverley Hall, dibujados por Nesfield en 1865-1870 y conservados en el Victoria \& Albert Museum (Calloway/Federle, 2011: 111, 113. Watanabe, 1991: fig. 12).

14 Gil, 1998: pp. 133-139. Bru, 2011: 804-805, 975-978. 


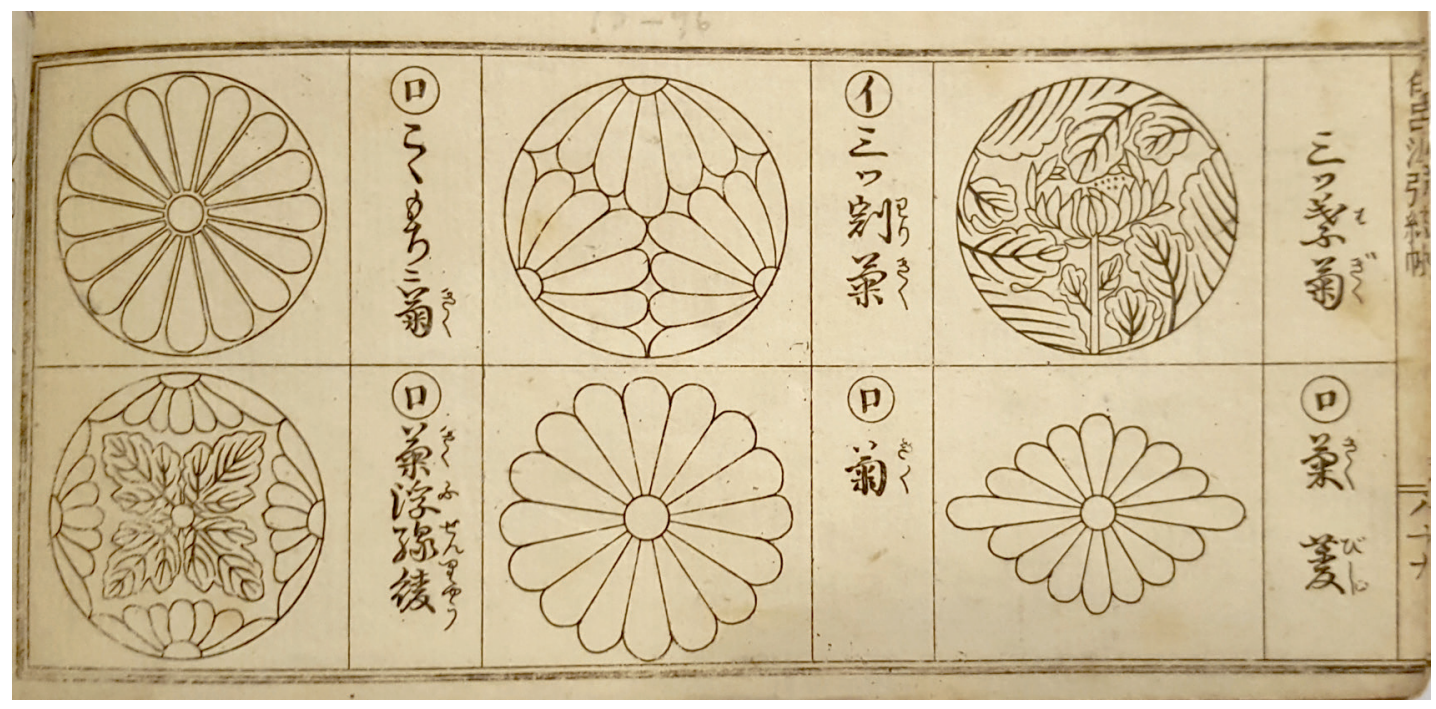

Fig. 2. Iroha-biki monchō, 1881. Antigua colección de Lluís Domènech i Montaner. AHCOAC H117C/11/26.

rante y la figura representado Japón esgrafiada por Saumell y Vilaró en la fachada del Gran Hotel Internacional de la misma Exposición Universal ${ }^{15}$.

La consulta de la Historia General del Arte, obra de capital importancia iniciada en 1886 bajo la dirección del arquitecto, pone de relieve que ya entonces su biblioteca contaba con varias obras dedicadas al arte japonés. Así, además de una copia de la edición francesa de 1865 del célebre volumen de Owen Jones, Grammar of ornament (1856), Domènech y Montaner fue adquiriendo otras publicaciones destacadas como L'empire japonais (1881), de L. Metchnikoff, Japan, it's architecture, art and art manufactures (1882), de Christopher Dresser, L'art japonais (1883), de Louis Gonse, Japanische Vorbilder (1886), de Heinrich Dolmetsch, y la revista Le Japon Artistique, editada por Siegfred Bing ${ }^{16}$. De hecho, los volúmenes I (1886), IV (1895), V (1897) y VIII (1897) de Historia General del Arte dedicados a la arquitectura, la pintura, la escultura, los tejidos y la cerámica, muestran el interés de todos los autores colaboradores por las artes de Japón con la inclusión de varios apartados específicos acompañados de más de un centenar de ilustraciones extraídas de obras de repertorios de láminas y de libros extranjeros como los de Gonse, Dresser y Dolmetsch, así como de colecciones catalanas, como la del ilustrador Josep Passos y la del propio arquitecto.

En este contexto, y ante este claro interés por Japón, cobran especial relieve otras expresiones artísticas que, de otro modo, podrían pasar más inadvertidas. Nos referimos especialmente a las placas de cristal con composiciones florales fotografiadas por Domènech, procedentes de la biblioteca particular del arquitecto y presentadas recientemente en la Casa Museo de Canet de $\operatorname{Mar}^{17}$. Se trata de un conjunto de veinte placas fotográficas, muchas de ellas mostrando especies vegetales propias del entorno del Maresme, que demuestran tanto un interés por la botánica como también una aproximación formal que se inclina hacia una estética de reminiscencias japonesas. Del mismo modo que las fotografías de flores de clivia (clivia nobilis) y rododendro (rhododen-

15 Ambos fueron dos proyectos decorativos de envergadura encargados por Domènech y Montaner a la empresa Saumell y Vilaró. En el caso del Café-Restaurant se trataba de un programa iconográfico (no finalizado) formado por numerosas figuras de todas las culturas y épocas que representaban las artes y los oficios, mientras que en el caso del Gran Hotel Internacional Saumell y Vilaró llevaron a cabo un extenso proyecto de decoración de las cuatro fachadas del edificio mediante esgrafiados que mostraban figuras que simbolizaban ciudades, regiones y países de todo el mundo.

16 Domenech, 1886: 145, 764, 768, 770, 772 y 766.

17 Sala/de la Fuente/López/Villar, 2013: 41-47. Sala, 2013: 128. 
dron ponticum) remiten a modelos como las fotografías de flores realizadas en el Japón del período Meiji y exportadas a Occidente contemporáneamente por fotógrafos como Ogawa Kazuma, otras imágenes muestran composiciones más complejas que en un caso llega hasta el punto de reproducir la bandera japonesa hinomaru junto con un arreglo floral que parece evocar las escenas naturales con flores de cerezo y flores de circuelo tan idiosincráticas del arte nipón ${ }^{18}$.

\section{La colección de libros ilustrados japoneses de Domènech i Montaner}

La muestra más clarividente de la atracción de Lluís Domènech i Montaner por el arte japonés es la colección de libros ilustrados que adquirió a finales del siglo XIX, conservada por los herederos y recientemente depositada en el Archivo Histórico del Colegio Oficial de Arquitectos de Cataluña (COAC). Nos referimos a un conjunto de veintiséis volúmenes ilustrados impresos en Japón entre finales del período Edo y la primera mitad del período Meiji ${ }^{19}$.

La colección comprendía obras especialmente populares en la época, como los tres volúmenes de las cien vistas del monte Fuji (Fugaku hyakkei, 1834-c.1849) de Katsushika Hokusai (fig. 3) y cuatro volúmenes del Manga (1814-1878) del mismo artista, junto con obras representativas de época Meiji, tales como volúmenes de imágenes de flores y pájaros de la escuela MaruyamaShijō, como la obra Bairei hyakuchō gafu (1881), de Kōno Bairei (fig. 4), o bien otros varios volúmenes ilustrados, ya fueran enciclopédicos o de temática mitológica y fantástica, de autores como Utagawa Kuniyoshi, Keisai Eisen y Katsushika Taito II. En términos generales, y como era habitual en las colecciones de la época, se trataba de un conjunto formado principalmente por reediciones y reimpresiones de época Meiji (Meiji-zuri) que respondía a los gustos, las preferencias y las demandas habituales que caracterizaron el fenómeno del japonismo en Europa de la segunda mitad de siglo. Eran, además, volúmenes populares que se podían adquirir en ciudades de Occidente a bajo coste y que acabaron siendo también comprados por compañeros catalanes del arquitecto, desde Apel·les Mestres y Alexandre de Riquer hasta Hermen Anglada Camarasa. En este sentido, resulta hasta cierto punto revelador comprobar como las mismas ediciones de algunas de las obras, como el volumen Kachō gafu - Jürui gafu, llegaron en las mismas fechas a las manos de otros artistas de la ciudad como Oleguer Junyent o Joan Vila. No solamente los títulos coinciden con los de otras bibliotecas japonesas del entorno del arquitecto sino que la temática y los motivos que dominan en la mayoría de las obras se corresponden igualmente con las preferencias de los artistas del modernismo, especialmente los diseños tan admirados de flores, pájaros, animales e insectos.

Desconocemos la procedencia precisa de los libros, aunque, analizando sus características, llegamos a la conclusión de que lo más probable es que la mayoría de ellos hubiesen sido comprados en alguna de las distintas tiendas de arte y productos japoneses de Barcelona. Los volúmenes de Senryūdō gafu incluyen el sello de origen de un establecimiento de libros antiguos japoneses, mientras que el primer volumen de Fugaku hyakkei conserva en la portada una etiqueta con la nota manuscrita 82 books single que podría indicar una procedencia inglesa. Sea como fuera, ambos casos vendrían a sustentar la hipótesis de que los volúmenes no fueron comprados en el pabellón japonés de la Exposición Universal de 1888, tal y como la tradición oral sostenía, sino que llegaron a manos de Domènech a través de las rutas comerciales habituales europeas $\mathrm{y}$, más concretamente, del comercio de arte japonés desarrollado con gran éxito a finales del ochocientos ${ }^{20}$.

\footnotetext{
18 Sala, 2013: 128.

19 Esta colección ha sido referenciada y citada en varias ocasiones en el contexto del japonismo y el coleccionismo de arte japonés en Cataluña, aunque ahora se presenta de forma completa por primera vez (Bru, 2013: 102. Bru, 2014: 72. Sala, 2014: 169. Bru, 2016: 6-8. Martí, 2016: 73).

${ }^{20}$ Hasta fechas tempranas, se pensaba que muchas de las estampas y libros ilustrados japoneses de antiguas colecciones que actualmente se conservan en Barcelona procedían de la Exposición Universal de 1888. Sin embargo, ahora sabemos que, salvo muy puntuales excepciones, la gran mayoría de las obras fueron adquiridas a lo largo de las dos últimas décadas del siglo XIX en establecimientos especializados, tanto de Barcelona como del extranjero.
} 

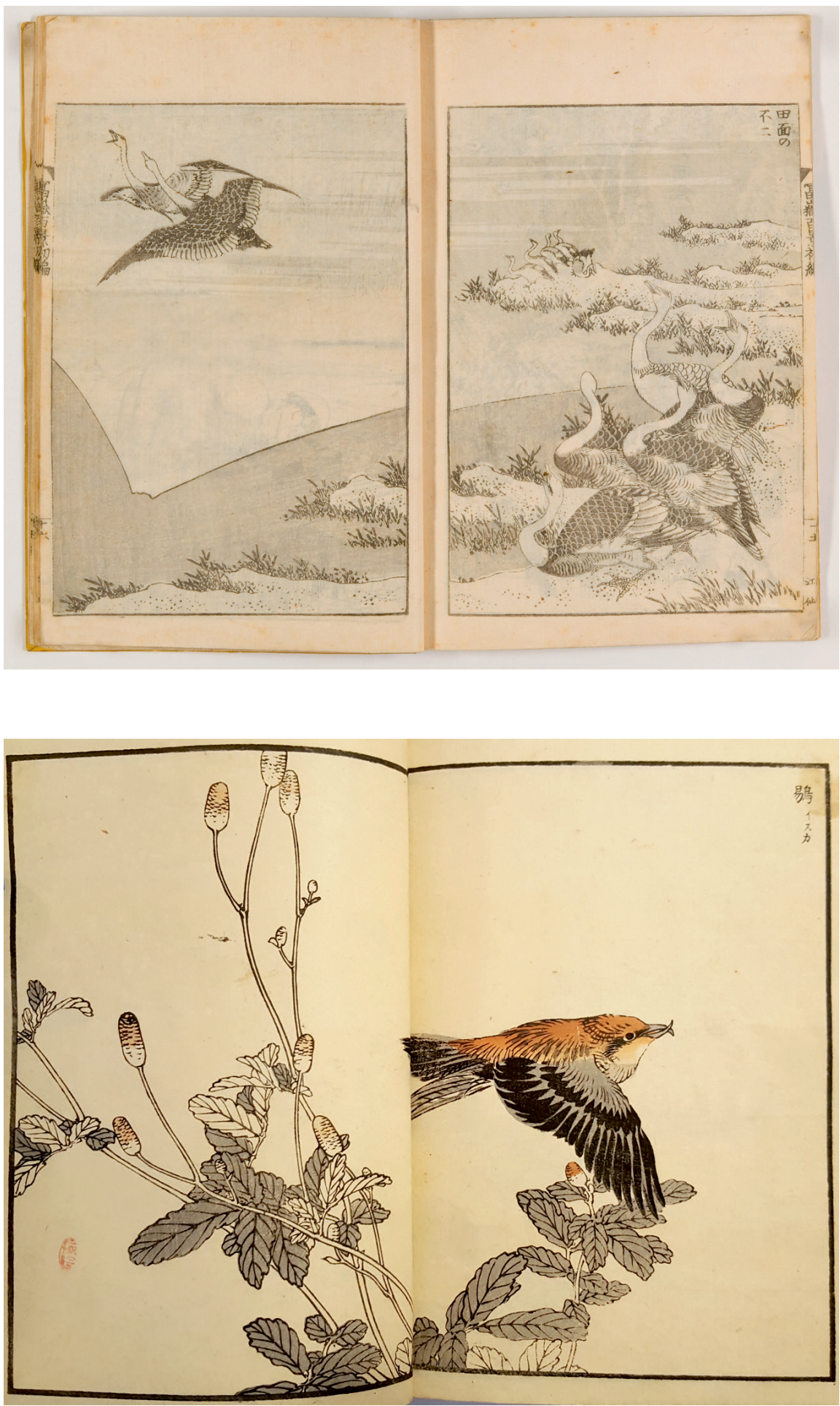

Fig. 3.

Katsushika

Hokusai,

Fugaku hyakkei, vol. 1 (1835) 1875. Antigua colección de Lluís Domènech i Montaner. COAC $\mathrm{H} 117 \mathrm{C} / 11 / 5$.
Fig. 4. Kōno

Bairei, Bairei hyakuchō gafu, vol. 3, 1881. Antigua colección de Lluís Domènech i Montaner. COAC H117C/11/2.

A pesar de no disponer de más datos ni documentos que la propia colección, todos los indicios, así como los vínculos que pueden extenderse en torno a la obra de Domènech i Montaner, permiten plantear la hipótesis de que la colección fue mayoritariamente comprada durante las 


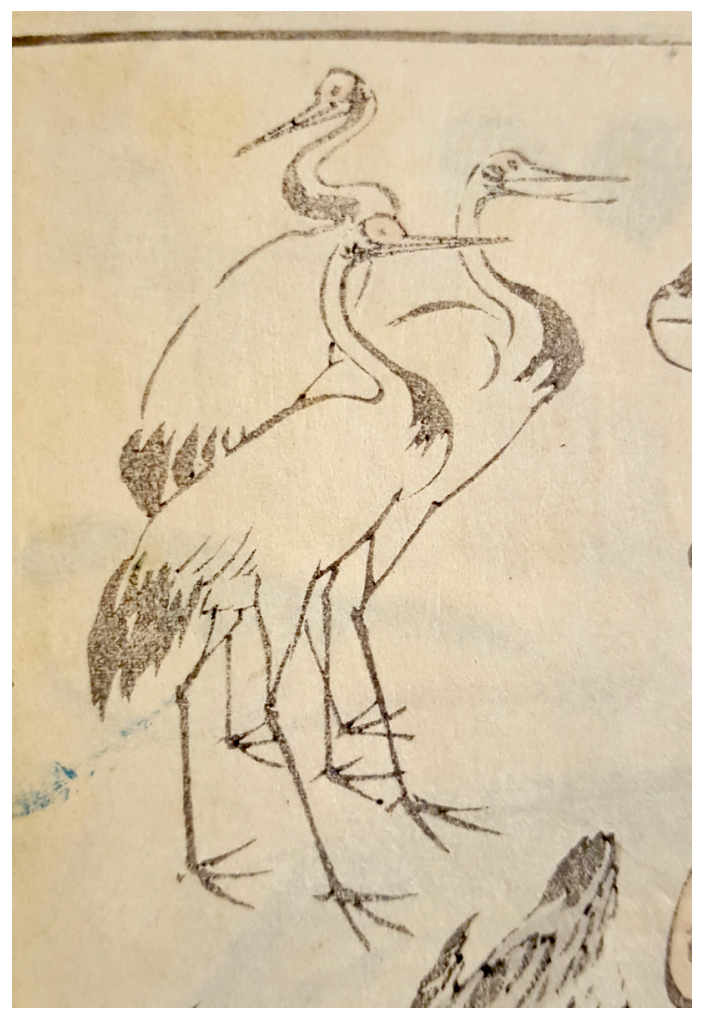

Fig. 5. Fragmento del volumen Ukiyo manga (1882), de Akiyama Kanichi, de la antigua colección de Lluís Domènech i Montaner. COAC H117C/11/21.

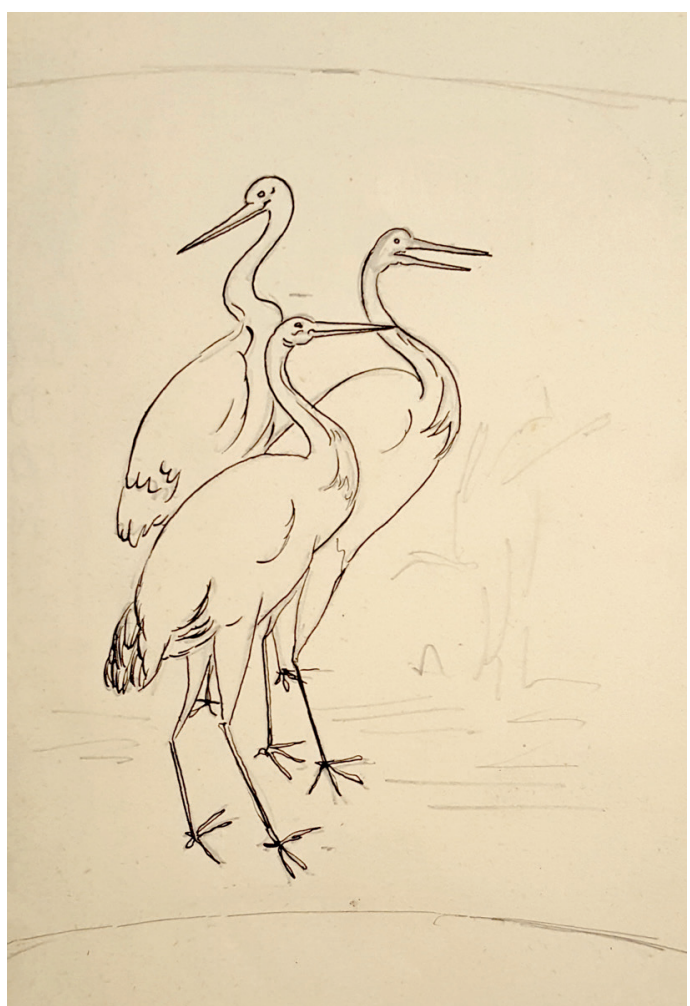

Fig. 6. Detalle de tres grullas copiadas por Lluís Domènech i Montaner del volumen Ukiyo manga (1882) para un posible proyecto de decoración de un abanico. COAC H117C/11/21.

décadas de 1880 y $1890,{ }^{21}$ en un momento previo al año 1903, tal vez en alguno de los varios establecimientos de arte japonés que a la sazón se abrieron en Barcelona. De lo que no hay duda es de que se trataba de un conjunto de libros que fueron hojeados con admiración y estudiados con detenimiento a finales de siglo. Prueba de ello son varias hojas, conservadas dentro del segundo volumen de la obra de Kōno Bairei, en las que aparecen copiadas varias grullas del libro Ukiyo manga (1882) (figs. 5-6), dentro de un marco en forma de abanico similar al que el arquitecto dibujó en la primera página ilustrada del tercer volumen de Bairei hyakuchō gafu (1881) (fig. 7). Igualmente, como en estos casos, muchos de los símbolos heráldicos del volumen Irohabiki monchō (1881) (fig. 2), fueron copiados y reseguidos con lápiz demostrando un mismo interés por el estudio de dichas formas, composiciones y diseños.

\section{El caso de la Fonda España}

Indicábamos el año 1903 como fecha ante quem ateniéndonos a que fue entonces, ese año, cuando se inauguró la reforma de la Fonda España, en la calle Sant Pau. Las obras llevadas a cabo en este céntrico hotel barcelonés, construido a mediados del siglo XIX, fueron dirigidas por Lluís Domènech y en ellas el arquitecto aplicó varios motivos extraídos claramente de su colec-

${ }^{21}$ Como hemos visto, ya en 1886 Domènech utilizó bibliografía dedicada al arte y la cultura japonesa aparecida a lo largo de la década de 1880 para redactar el primer volumen de la Historia General del Arte. 


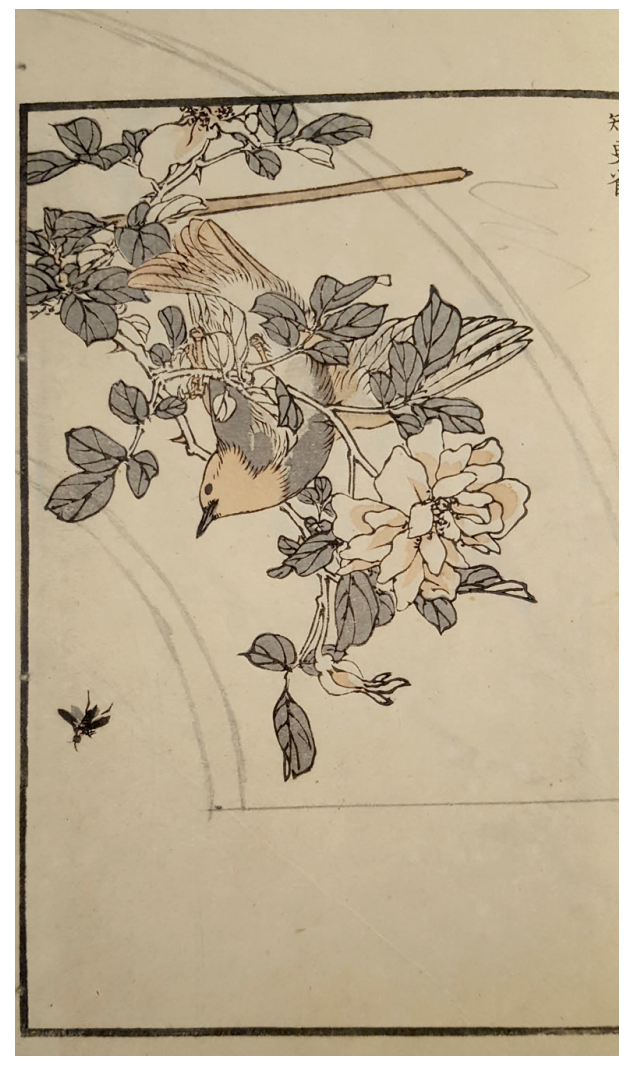

Fig. 7. Kōno Bairei, Bairei hyakuchō gafu, vol. 2, 1881. Diseño inscrito dentro de un marco dibujado a lápiz en forma de abanico. Antigua colección de Lluís Domènech i Montaner. COAC H117C/11/1.

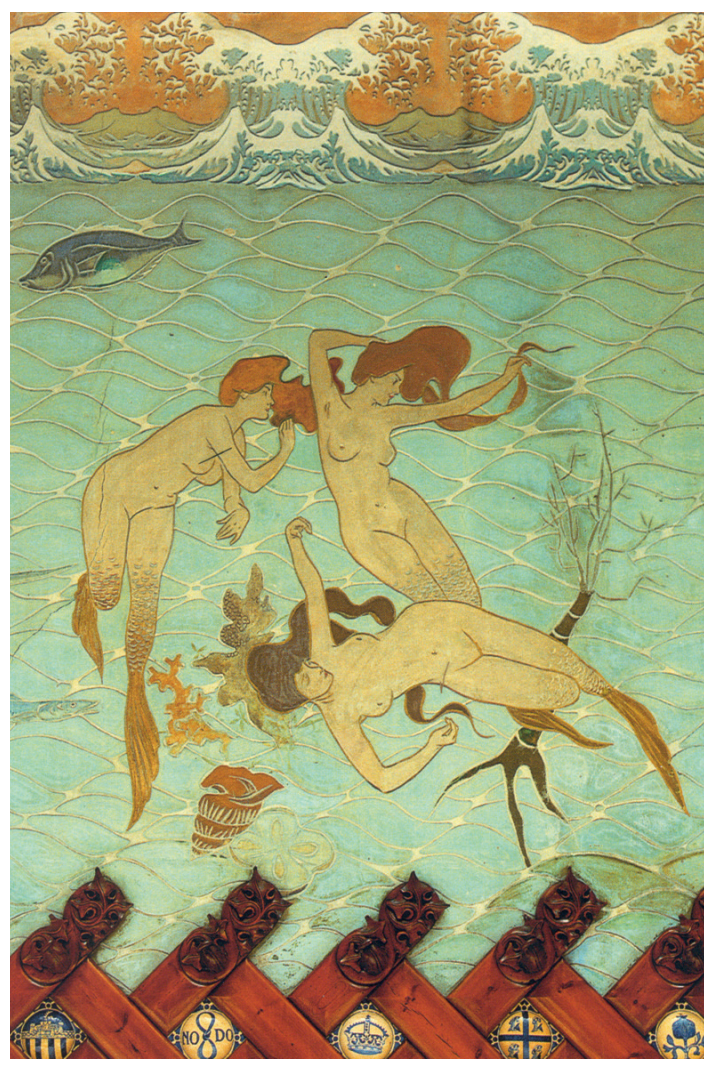

Fig. 8. Salón de las Sirenas presidido por cuatro nereidas acompañadas por una dorada, un pez corneta, fragmentos de coral, una caracola de mar y un erizo clypeaster japonicus. Fonda España, 1903.

ción de libros japoneses. Y es que el comedor conocido como "Salón de las sirenas", tan elogiado en la época y presentado en varias ocasiones en relación con el japonismo, ${ }^{22}$ es la constatación más palpable no sólo del interés de Domènech por el arte japonés, sino también del hecho de que el arquitecto ya tenía en sus manos unos libros ilustrados que le sirvieron de inspiración y de modelo para plantear una decoración tan moderna como original.

Tal y como constatan los periódicos de la época, no hay duda de que Ramon Casas fue el autor del decorado de las paredes del comedor, "hermosamente esgrafiadas con figuras de nereidas y gran cantidad de peces y carolinas dentro de transparencias de agua" (fig. 8) ${ }^{23}$. Casas trazó las formas de las sirenas, ninfas o nereidas que nadan libremente por el fondo marino de la sala, así como el resto de imágenes del salón. Sin embargo, tal y como destaca Gemma Martí, Domènech jugó un papel igualmente destacado al plantear una decoración basada en la técnica del esgrafiado en lugar de optar por encargar a Casas un conjunto de pinturas al óleo como el que acababa de realizar para el Círculo del Liceo (1902). Aun más, es altamente probable que la concepción global de toda la decoración marina fuera fruto del trabajo colaborativo entre Casas

22 El japonismo en la Fonda España ha sido tratado ya en múltiples ocasiones. Véase: Bru, 2012: 32-33. Cabañas, 2013: 385-403. Martí, 2016: 58-79. Bru, 2016: 6-8.

23 Traducción del catalán realizada por el autor. "La Fonda d'Espanya", Ilustració Catalana, núm. 103, 21 de mayo de 1905, p. 328. Véase también: La Veu de Catalunya, núm. 2223, 20 de mayo de 1905 (edición de noche), p. 2 (Permanyer, 2004: 7). 


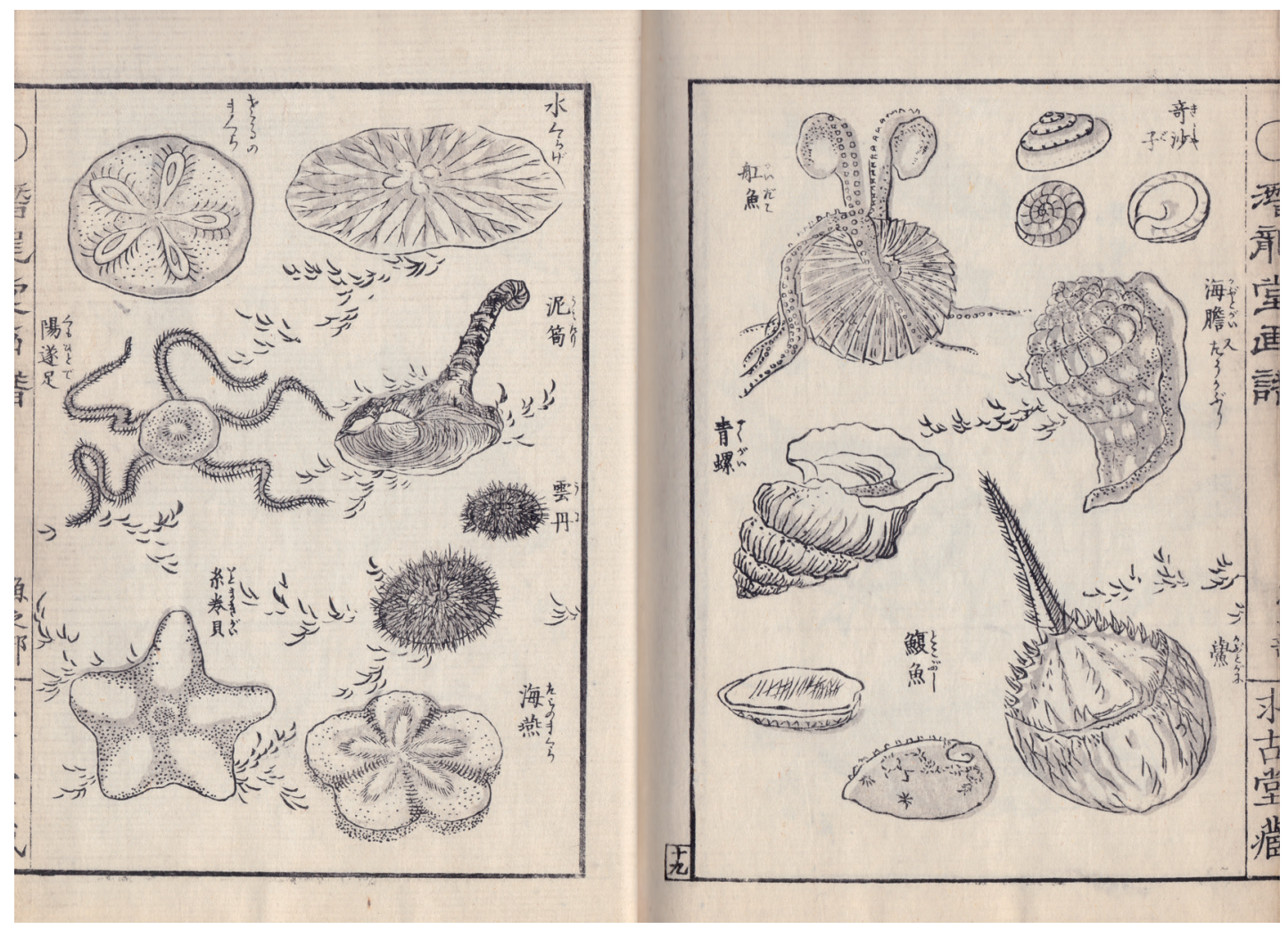

Fig. 9. Takizawa Kiyoshi, Senryūdō gafu - Gyorui no bu (Uo no bu), 1880. Doble página en la cual aparecen algunos de los seres copiados por Casas en el Salón de las Sirenas. COAC H117C/11/13.

y Domènech planteando un proyecto que, en última instancia, acabó realizando alguna empresa especializada en la producción de esgrafiados de estuco y la decoración de interiores. Hacemos esta precisión porque, si bien los periódicos atribuían a Casas la autoria de la decoración, prácticamente todos los motivos marinos del comedor fueron extraídos de forma mimética y exacta de las páginas de uno de los libros ilustrados japoneses de la biblioteca de Domènech Montaner: el volumen Gyorui no bu, de la obra Senryūdō gafu de Takizawa Kiyoshi, impreso el año 1880.

A pesar de que hasta ahora se habían comparado los motivos marinos del Salón de las Sirenas principalmente con las ilustraciones de los volúmenes del Hokusai Manga, una hipótesis avalada por la similitud de ciertos diseños y la fama que la obra de Hokusai tenía en la Europa de finales del ochocientos, ${ }^{24}$ lo cierto es que dicho comedor, conocido también como la pecera, es en sí mismo la traducción modernista, a través de los ojos de Ramon Casas, de la obra de otro artista mucho menos conocido, Takizawa Kiyoshi. Allí aparecen nadando de forma libre y aparentemente azarosa todo tipo de peces de las costas japonesas, desde doradas (fuefukidai), filistularias (yagara), peces luna (manbō) y rayas (akaei), hasta rapes (ankō), jureles (shimaaji) y peces voladores (tobinouwo), todos ellos acompañados de cabrachos (onikasago), sepias (ika), pulpos (tako), calamares (surume-ika), langostinos (kuruma ebi), gambas (ebi), cangrejos (shimagani), estrellas de mar (hitode, momijigai), caracolas (sazae, seira), ofiuroideos (kumohitode), medusas (umi no kurage) y otras especies características de Japón, como los Clypeaster japonicus (takonomakura), todas ellas identificadas con precisión en el volumen ilustrado de Takizawa (fig. 9). Por si fuera poco, toda esa extensa y rica representación marina nipona aparece coronada con un

${ }^{24}$ Mabuchi, 2017: 127-157. 


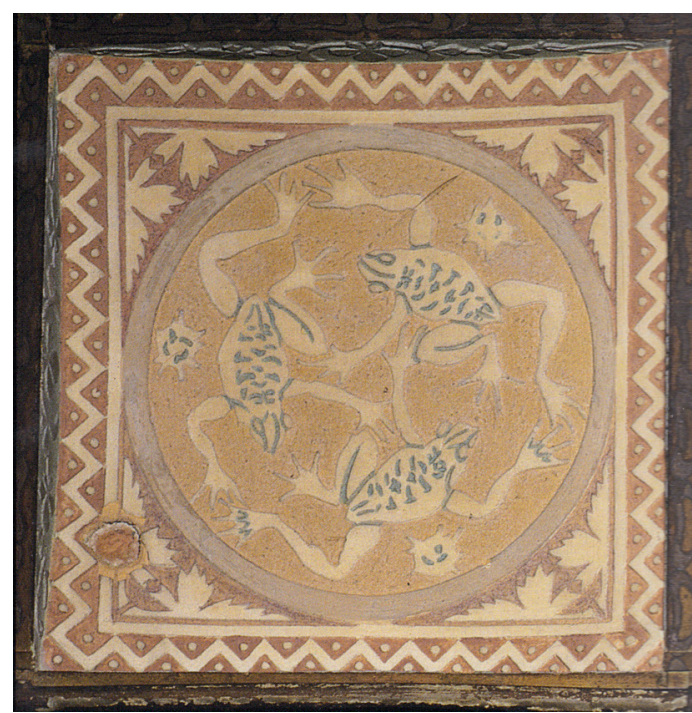

Fig. 10. Casetón del techo del Salón de las sirenas representando a tres ranas. Fonda España, 1903.

Fig. 11. Akiyama Kanichi, Ukiyo manga, 1882. Ilustración de una rana extraída del primer volumen del Hokusai Manga (1814). Antigua colección de Lluís Domènech i Montaner. COAC H117C/11/21.

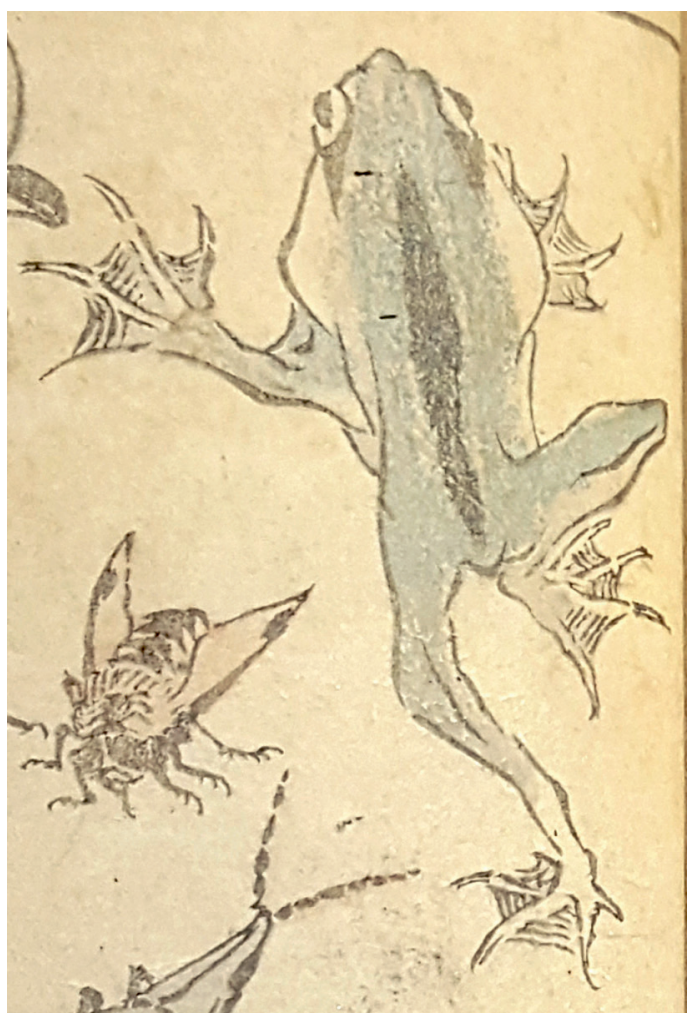

friso superior en el que se repite de forma continuada la famosa Ola de Kanagawa, de la serie de Treinta y seis vistas del monte Fuji de Hokusai, a la sazón ya ampliamente conocida en toda Europa. El salón puede considerarse, en definitiva, todo un homenaje al mar de Japón.

La ascendencia japonesa del comedor de los huéspedes de la Fonda España va más allá de la ola de Hokusai y de la profusión de seres marinos extraídos de la colección del arquitecto. Los casetones del techo, por ejemplo, están decorados con motivos circulares dentro de los cuales se pueden ver otros animales y plantas tales como un erizo, conchas, caracoles de mar, libélulas y un cangrejo. Entre ellos, aparecen varias formas claramente inspiradas en los modelos japoneses, tal y como lo demuestran, por ejemplo, los casetones decorados con tres ranas (fig. 10) extraídas tal vez del tercer volumen de la obra Ukiyo manga (1882), localizados en la misma biblioteca del arquitecto (fig. 11) ${ }^{25}$. Asimismo, el modo de disponer los motivos decorativos de cada uno de los casetones de la techumbre dentro de un marco circular podría partir de los motivos circulares que llenaban las páginas del volumen Iroha-biki monchō (1881), así como de otras posibles obras recurrentemente utilizadas por los artistas del momento. En efecto, contemporáneamente, Víctor Oliva, Adrià Gual, Alexandre de Riquer y otros artistas y arquitectos del modernismo

${ }^{25}$ Como sucede en el caso de los diseños circulares mon, algunos los animales utilizados por Domènech para decorar los casetones aparecen en numerosas publicaciones de la época, motivo por el cual difícilmente puede señalarse con seguridad una única fuente. A modo de ejemplo, en el caso de las ranas, dicho diseño fue dibujado inicialmente por Katsushika Hokusai; aparece por primera vez en el primer volumen del Hokusai manga (1814) y fue reproducido en revistas, en libros y manuales de repertorios artísticos tales como los del barón Charles de Chassiron (Notes sur le Japón, La Chine et L'Inde, 1864), Thomas W. Culter (A grammar of Japanese ornament and design, 1880), Eugène-Victor Collinot (Ornements du Japon, 1883), Louis Gonse (L'Art Japonais, 1883) o Siegfried Bing (Le Japon Artistique, 18881891). No es de extrañar, por lo tanto, que apareciera frecuentemente como motivo japonés en obras europeas de finales de siglo diecinueve (Cabañas, 2013: 400. Mabuchi, 2017: 43, 155-156). 


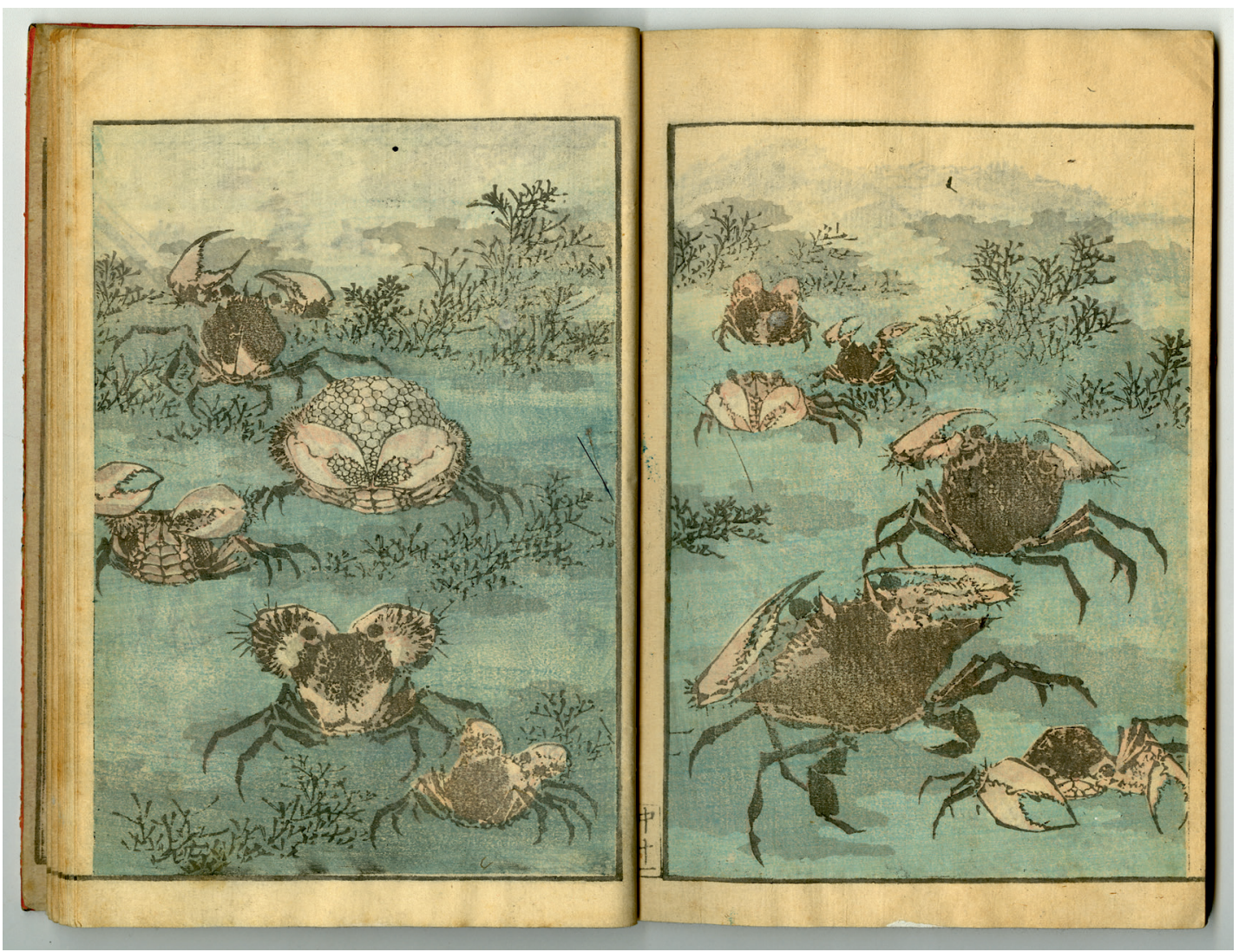

Fig. 12. Katsushika Taito II, Kachō gaden, volumen 2, c. 1870 (1848). Antigua colección de Lluís Domènech i Montaner. COAC H117C/11/19.

incorporaron la modernidad de los motivos circulares japoneses a todo tipo de propuestas, desde la creación de sellos, exlibris y encuadernaciones como el anteriormente citado Aplech de Blancafort, hasta la decoración para esgrafiados de fachadas, como la de la Casa Miquel Call Millàs del barrio de Gracia, proyectada por Joan Marsant en 1893 y popularmente conocida como "la casa de les besties" 26 . Junto con todo ello, además, es posible que, tal y como apunta Pilar Cabañas, hubiera otros elementos del proyecto decorativo del salón, tales como el diseño de listones trenzados del arrimadero, que pudieran haber partido de modelos igualmente japoneses ${ }^{27}$. En definitiva, Casas y Domènech convirtieron el Salón de las sirenas en la simbiosis perfecta entre el modernismo y el arte japonés y en lo que podemos llegar a considerar como uno de los espacios más paradigmáticos del japonismo en la arquitectura catalana del 1900.

${ }^{26}$ En la fachada de la Casa Call Millàs aparecen treinta y ocho animales entre los cuales se encuentran algunos de los representados en el salón de las sirenas de la Fonda España, tales como el pez luna, la raya y la libélula (Permanyer, 2000: 5. Pifarrré, 2014: 176-177).

27 La propia idea de plantear un techumbre de casetones con unos extremos curvados que confluyen con los muros podría haber sido sacado de los modelos aportados por Christopher Dresser en el volumen adquirido y estudiado por Domènech (Cabañas, 2013: 395). 


\section{A modo de conclusión}

A lo largo de las últimas décadas, han podido ser documentadas y localizadas cuantiosas colecciones de arte japonés pertenecientes a burgueses y artistas catalanes protagonistas del modernismo y el novecentismo, muchas de ellas conservadas aún por sus herederos, que han modulado y enriquecido nuestro conocimiento del japonismo y la incidencia de éste en la evolución del arte creado en la Cataluña del último tercio del siglo XIX y la primera mitad del siglo XX. Sin el conocimiento de las colecciones de Alexandre de Riquer, Lluís Masriera o de Joan Vila, por ejemplo, difícilmente se puede comprender de forma completa parte de sus obras. Desde este punto de vista, son muchos los casos en los que el coleccionismo de arte japonés, junto con el estudio comparativo de las obras artísticas creadas por sus propietarios, depararán aun, sin duda alguna, nuevas sorpresas.

Recientemente se presentaron dos volúmenes en los que por primera vez se recogía toda la obra arquitectónica de Lluís Domènech i Montaner $^{28}$. Si el catálogo razonado daba a conocer obras del arquitecto hasta el momento desconocidas, parece evidente que sus proyectos arquitectónicos, y artísticos si lo consideramos en términos más generales, permiten nuevas miradas. Del mismo modo que hemos podido demostrar el reflejo evidente del japonismo en varios de sus proyectos, confiamos en que la presentación de la colección de libros ilustrados japoneses (fig. 12), adquiridos hacia finales del siglo XIX por el arquitecto, permita en el futuro nuevas lecturas de aspectos concretos de la obra arquitecto aún por revelar.

\section{CATALOGACIÓN DE LA COLECCIÓN DE LIBROS ILUSTRADOS JAPONESES PERTENECIENTES A LA ANTIGUA BIBLIOTECA DE LLUÍS DOMĖNECH I MONTANER}

COAC H117C/11/1

Kōno Bairei, Bairei hyakuchō gafu, vol. 2, Ōkura Magobē, 1881. Ōhon $(25 \times 16,5$ cm).

COAC H117C/11/2

Kōno Bairei, Bairei hyakuchō gafu, vol. 3, Ōkura Magobē, 1881 (reencuadernación de 1884). Ōhon $(24,8 \times 16,6 \mathrm{~cm})$.

COAC $\mathrm{H} 117 \mathrm{C} / 11 / 3$

Kōno Bairei, Bairei hyakuchō gafu, vol. 1, Ōkura Magobē, 1881. Ōhon $(24,8 \times 16,5$ cm).

COAC H117C/11/4

Kōno Bairei, Bairei hyakuchō gafu, vol. 2, Ōkura Magobē, 1881. Ōhon $(24,8 \times 16,6$ cm).

$\mathrm{COAC} \mathrm{H} 117 \mathrm{C} / 11 / 5$

Katsushika Hokusai, Fugaku hyakkei, vol. 1, Eirkuya Tōshirō (Katano Tōshirō), 1875 (primera edición de 1834). Hanshibon $(22,6 \times 15,8 \mathrm{~cm})$.

COAC H117C/11/6

Katsushika Hokusai, Fugaku hyakkei, vol. 2, Eirkuya Tōshirō (Katano Tōshirō), 1875 (primera edición de 1835). Hanshibon $(22,6 \times 15,7 \mathrm{~cm})$.

\section{COAC H117C/11/7}

Katsushika Hokusai, Fugaku hyakkei, vol. 3, Eirkuya Tōshirō (Katano Tōshirō), 1875 (primera edición de c.1849). Hanshibon $(22,5 \times 15,8 \mathrm{~cm})$.

\section{COAC H117C/11/8}

Katsushika Hokusai, (Denshin kaishu) Hokusai manga, vol. 11, Eirkuya Tōshirō (Katano Tōshirō), 1875 (primera edición de c. 1834). Hanshibon $(22,5 \times 15,8 \mathrm{~cm})$.

\footnotetext{
28 Alcalde et alii, 2016.
} 
COAC H117C/11/9

Katsushika Hokusai, (Denshin kaishu) Hokusai manga, vol. 10, Eirkuya Tōshirō (Katano Tōshirō), 1875 (primera edición de 1819). Hanshibon $(22,4 \times 15,8 \mathrm{~cm})$.

COAC H117C/11/10

Katsushika Hokusai, (Denshin kaishu) Hokusai manga, vol. 7, Eirkuya Tōshirō (Katano Tōshirō), 1875 (primera edición de 1817). Hanshibon $(22,5 \times 15,7 \mathrm{~cm})$.

COAC H117C/11/11

Katsushika Hokusai, (Denshin kaishu) Hokusai manga, vol. 3, Eirkuya Tōshirō (Katano Tōshirō), 1875 (primera edición de 1815). Hanshibon $(22,5 \times 15,7 \mathrm{~cm})$.

COAC H117C/11/12

Takizawa Kiyoshi, Senryūdō gafu - Jinbutsu no bu, Matsuzaki Hanzō, Ōtsuka Tetsugorō, 1882. Hanshibon $(22,4 \times 15,2 \mathrm{~cm})$.

COAC $\mathrm{H} 117 \mathrm{C} / 11 / 13$

Takizawa Kiyoshi, Senrȳ̄ōo gafu - Gyorui no bu (Uo no bu), Matsuzaki Hanzō, 1880. Hanshibon $(22,3 \times 15,1 \mathrm{~cm})$.

COAC H117C/11/14

Takizawa Kiyoshi, Senryūdō gafu - Kusabana mushi no bu, Matsuzaki Hanzō, Ōtsuka Tetsugorō, 1881. Hanshibon $(22,4 \times 15,2 \mathrm{~cm})$.

COAC H117C/11/15

Keisai Eisen, Ukiyo gafu, vol. 2, siglo XIX (primera edición de c. 1830). Hanshibon (22,6 × 15,8 cm). COAC H117C/11/16

Keisai Eisen, Ukiyo gafu, vol. 1, siglo XIX (primera edición de c. 1830). Hanshibon (22,4 × 15,7 cm). COAC H117C/11/17

Utagawa Kuniyoshi, Shinji andon, vol. 2, Kōbaien, segunda mitad del siglo XIX (primera edición de c. 1830). Hanshibon $(22,4 \times 15,6 \mathrm{~cm})$.

COAC H117C/11/18

Maki Bokusen, Kyōgaen, vol. 1, segunda mitad del siglo XIX (primera edición de 1809). Hanshibon $(22,6 \times 15,8 \mathrm{~cm})$.

COAC H117C/11/19

Katsushika Taito II, Kachō gaden, vol. 2, Sūzanbō, segunda mitad del siglo XIX (primera edición de 1848). Hanshibon $(22,3 \times 15,8 \mathrm{~cm})$.

COAC H117C/11/20

Katsushika Hokusai, Hokusai gafu, vol. 2, tercer cuarto del siglo XIX (primera edición de 1820). Hanshibon $(22,5 \times 15,8 \mathrm{~cm})$.

COAC $\mathrm{H} 117 \mathrm{C} / 11 / 21$

Akiyama Kanichi, Ukiyo manga, Funai Masataro, Onoki Ichibe, 1882. Chūbon $(17,6 \times 12 \mathrm{~cm})$.

COAC H117C/11/22

Utagawa Sadahide, Banshō shashin zufu, vol. 1, Abe Yoshitō, Kogenchikudō, segunda mitad del siglo XIX. Chübon $(17,8 \times 11,8 \mathrm{~cm})$

COAC H117C/11/23

Utagawa Yoshimura, Jūrui gafu, Ōhashidō, c. 1880. Chūbon $(17,8 \times 11,5 \mathrm{~cm})$

COAC H117C/11/24

Utagawa Yoshimura, Kachō gafu - Jūrui gafu, Ōhashidō, c. 1880. Chübon $(17,9 \times 11,6 \mathrm{~cm})$

COAC H117C/11/25

Utagawa Yoshiharu, Jinbutsu gafu, Ōhashidō, c. 1880. Chūbon $(17,8 \times 11,5 \mathrm{~cm})$.

COAC H117C/11/26

Tanaka Kikuo, Iroha-biki monchō, Matsuzaki Hanzō, 1881. Yokobon $(7,5 \times 15,8 \mathrm{~cm})$. 


\section{BIBLIOGRAFÍA}

Alcalde Vilà, Sergi et alii (2016): Lluís Domènech i Montaner. Obra arquitectònica raonada (volumen 1 y 2). Canet de Mar: Centre d'Estudis Lluís Domènech i Montaner, Canet de Mar.

Arnús, María del Mar (2004): Comillas. Preludio de la modernidad. Mallorca: Triangle postals.

Bletter, Rosemarie (1977): El arquitecto Josep Vilaseca i Casanovas. Sus obras y dibujos. Barcelona: La Gaya Ciencia.

Bru, Ricard (2007): “Interiors japonesos a la Barcelona del vuit-cents”. En: Jornades Internacionals Espais Interiors. Casa i Art. Barcelona, Universitat de Barcelona, pp. 53-61.

Bru, Ricard (2011): Els orígens del japonisme a Barcelona. La presència del Japó a les arts del vuit-cents (1868-1888). Barcelona, Insitut d'Estudis Món Juïc.

Bru, Ricard (2012): "Hokusai a Catalunya". En: Serra d'Or, 629, mayo de 2012, Barcelona, pp. 32-33.

Bru, Ricard (ed.) (2013): Japonismo. La fascinación por el arte japonés. Barcelona, Obra Social La Caixa.

Bru, Ricard (2014): "El col·leccionisme d'art de l'Àsia Oriental a Catalunya (1868-1936)". En: Bassegoda, Bonaventura / Domènech, Ignasi (ed.): Mercat de l'art, col·leccionisme i museus. Estudis sobre el patrimoni artístic a Catalunya als segles XIX $i$ XX. Bellaterra: Memoria Artium 17, pp. 51-86.

Bru, Ricard (2016): “La Fonda España de Lluís Domènech i Montaner. Un japonismo de libro”. En: Eikyo, núm. 22, Barcelona, pp. 6-8.

Bru, Ricard (2017): "Baruserona no japonisumu”. En: Kinoshita Akira (ed.): Baruserona katarūnya bunka no saisei to tenkai. Tokio: Chikurinsha, pp. 209-225.

Cabañas, Pilar (2013): "Lluís Domènech i Montaner y Ramon Casas en La Fonda de España: Modernismo y Japonismo en Barcelona”. En: Artigrama, 28, Zaragoza, pp. 385-403.

Calloway, Stepgen / Federle Orr, Lynn (2011): The Cult of Beauty: The Aesthetic Movement 1860-1900. Londres, Victoria \& Albert Publishing.

Cutler, Thomas W. (1880): A grammar of Japanese ornament and design with an introductory, descriotive and analytical text. Londres, B. T. Batsford.

Domenech, Luís (1886): Historia General del Arte, vol. 1. Barcelona: Montaner y Simon.

García Llansó, Antonio (1888): “La exposición universal de Barcelona. La casa japonesa”. En: La Ilustración. Revista hispano-americana, 400, 1 de julio de 1888, Barcelona, pp. 417-418, 425, 431.

Gil Farré, Núria (1998): "La influencia del arte japonés en el diseño de vidrieras modernistas". En: Actas del XII Congreso Nacional del Comité Español de Historia del Arte. Oviedo, pp. 133-139.

Mabuchi, Akiko (ed.) (2017): Hokusai and japonisme. Tokio, The National Museum of Western Art.

Martí Rey, Gemma (2016): "L'obra de Ramon Casas a la Fonda Espanya. La influència del japonisme a la sala dels hostes". En: Domenechiana, IV, 7, Canet de Mar, pp. 58-79.

Permanyer, Lluís (2000): "Derramó el zoo en plena fachada". En: La Vanguardia, 42.736, Suplemento Vivir en Barcelona, 29 de octubre de 2000 , p. 5.

Permanyer, Lluís (2004): “Casas pintó el mural de las sirenas”. En: La Vanguardia, 43.996, Suplemento Vivir en Tarragona, 24 de abril de 2004, p. 7.

Pifarré Yañez, Daniel (2014): "Els animals en 1'esgrafiat del modernisme”. En: Capellà, Pere; Galmés, Toni (eds.): Arts $i$ naturalesa. Biologia i simbolisme a la Barcelona del 1900. Barcelona: Universitat de Barcelona, 2016, pp. 171-178.

Sala, Teresa-M. / de la Fuente, Vicente / López, Fàtima / Villar, Vànelis (2013): "Flors domenequianes". En: Empremtes, Lluís Domènech i Montaner a Canet de Mar, Canet de Mar: Casa Museu Lluís Domènech i Montaner, pp. 30-47.

Sala, Teresa-M. (2013): “Japonismo y modernismo: una simbiosis estética”. En: Bru, Ricard (ed.): Japonismo. La fascinación por el arte japonés. Barcelona, Obra Social La Caixa, pp. 127-131.

Sala, Teresa-M. (2014): "L'estudi del bestiario modernista. Apunts per a una primera aproximació”. En: Capellà, Pere; Galmés, Toni (eds.): Arts i naturalesa. Biologia i simbolisme a la Barcelona del 1900. Barcelona: Universitat de Barcelona, 2016, pp. 153-170.

Torii, Tokutoshi (2002): "Gaudí i la cultura japonesa”. En: Gaudi 2002. Miscel·lània. Barcelona: Ajuntament de Barcelona, pp. 118-137.

Watanabe, Toshio (1991): High Victorian Japonisme. Londres: Peter Lang.

Fecha de recepción: 22-III-2017

Fecha de aceptación: 30-X-2017

Archivo Español de Arte, vol. XCI, n. ${ }^{\circ}$ 363, pp. 285-300, julio-septiembre 2018

ISSN: 0004-0428, eISSN: 1988-8511, https://doi.org/10.3989/aearte.2018.18 